surveillance, and increased parental and professional awareness could provide more accurate early detection of LD children.

\title{
BUSSELTON STUDY OF BEHAVIOR DISORDER PREVENTION
}

The long-term follow-up in 1993 of 209 adults, aged 27 to 29 years, who as children were enrolled in the Busselton Population six-year controlled study of prevention of children's behavior disorders is reported from Claremont, Western Australia. Ninety percent of the original cohort responded to a questionnaire detailing their present social situation and habits, educational achievements, and emotional well-being. In the initial Busselton study, 1964-1973, a 20- to 30-minute interview between physician and mother about the preschool child had reduced the incidence of behavioral disturbances at age 6 years. As adults, the study subjects had fewer neurotic symptoms and less depressive symptoms than controls, and more had a university degree. Study women were less obese and smoked less than controls. Behavior patterns noted at 6 years of age after preschool interventional counselling were reflected in the improvements recorded as adults when compared to controls. (Cullen KJ, Cullen AM. Long-term follow-up of the Busselton six-year controlled trial of prevention of children's behavior disorders. I Pediatr July 1996;129:136-9). (Reprints: Dr AM Cullen, 37 Riley Rd, Claremont 6010, Western Australia).

COMMENT. The interviewing and counselling of mothers of preschool children benefits the children's behavior at 6 years of age, and leads to increased emotional well-being and higher academic achievement in adult life. Women were benefited more than men. The decrease in eating problems among study children at 6 years of age were relected in the lesser incidence of obesity, less anxiety and depressive symptoms, and reduced tendency to smoke in female study subjects. University degrees had been attained by $34 \%$ of experimental women compared to $24 \%$ of the male subjects and $15 \%$ of both male and female controls.

In my ADHD Clinic at Children's Memorial Hospital, Chicago, I am continually impressed and concerned regarding the frequent negative approach of parents to the management of their hyperactive children. The adoption of a positive and gentle parental attitude toward modifying a child's behavior, as promoted in the Busselton study, should be encouraged early in a child's development. The obvious importance of services and expertise of child and family psychologists in County and City Mental Health Programs should be emphasized in Federal, State, and City government.

\section{STIMULANT THERAPY FOR BENIGN CHOREA AND ADHD}

A 6-year-old boy with benign familial chorea diagnosed at 1 year and ADHD evaluated and treated with methylphenidate (MPH) at 6 years is reported from the Department of Pediatrics, David Grant Medical Center, Travis Air Force Base, California. After MPH beginning with $2.5 \mathrm{mg}$ BD and gradually increasing to $7.5 \mathrm{mg} \mathrm{BD}$, his attention span, self-control, handwriting, and school performance were benefited as expected, but in addition, the chorea improved and his independent walking skills developed. On drug holidays, the chorea and gait problems regressed. (Friederich RL. Benign hereditary chorea improved on stimulant therapy. Pediatr Neurol May 1996;14:326-27). (Respond: Dr Friedrich, 60 MOS/SGOC, 101 Bodin Circle, Travis AFB, CA 94535).

COMMENT. The author suggests that chorea complicating ADHD should 
not contraindicate a cautious trial of stimulant medication. If methylphenidate improves a child's performance in school and lessens stressful situations, it may also result in a reduction in chorea and improved motor abilities.

\section{SEIZURE DISORDERS}

\section{EARLY SEIZURES AND HIPPOCAMPAL PATHOLOGY}

The relation of childhood seizures to hippocampal neuron loss, mossy fiber synaptic reorganization, and eventual hippocampal sclerosis was investigated at the Brain Research Institute, University of California, Los Angeles, and the Cleveland Clinic Foundation, OH. Surgical epilepsy cases had generalized seizures and extra-hippocampal prenatal cortical dysplasia or postnatal ischemic and encephalitic lesions, or complex partial hippocampal epilepsy. Extra-hippocampal childhood seizures of prenatal or postnatal etiology were associated with moderate fascia dentata and minimal Ammon's horn neuron losses and signs of aberrant mossy fiber sprouting. Children with mesial temporal epilepsy showed patterns of neuron loss and mossy fiber sprouting, typical of adult form hippocampal sclerosis, whereas repeated extra-hippocampal generalized seizures were not associated with progressive hippocampal damage and sclerosis. (Mathern GW, Babb TL, Mischel PS et al. Childhood generalized and mesial temporal epilepsies demonstrate different amounts and patterns of hippocampal neuron loss and mossy fibre synaptic reorganization. Brain June 1996;119:965-987). (Respond: Gary W Mathern MD, Division of Neurosurgery, Reed Neurological Research Center, UCLA Medical Center, Los Angeles, CA 90095).

COMMENT. The authors conclude that childhood seizures can damage postnatal development of hippocampal granule cells, contributing to chronic hippocampal complex partial epilepsy. Generalized seizures are not a cause of hippocampal sclerosis.

\section{HEMIFACIAL SEIZURES AND CEREBELLAR GANGLIOGLIOMA}

A female infant with cerebellar ganglioglioma who developed hemifacial seizures from the first day of life is reported from the Miami Children's Hospital, FL. When investigated at 6 months of age there were daily episodes of left hemifacial contraction, resistant to medication, head and eye deviation to the right, nystagmoid jerks to the right, autonomic dysfunction, while consciousness was retained. MRI at 2 months showed a mass in the left cerebellar hemisphere. The scalp EEG recordings were normal, while interictal and ictal intracranial EEGs revealed focal spikes, confirming seizures arising in the region of the left cerebellar mass. Partial resection of a ganglioglioma at 3 months was accompanied by remission of seizures. Six previous reports of infants with hemifacial spasms and cerebellar mass lesions are cited in the literature and reviewed, 3 having gangliogliomas. (Harvey AS, Jayakar P, Duchowny M, Resnick T, Renfroe JB et al. Hemifacial seizures and cerebellar ganglioglioma: an epilepsy syndrome of infancy with seizures of cerebellar origin. Ann Neurol July 1996;40:91-98). (Respond: Dr Jayakar, Neuroscience Center, Miami Children's Hospital, 3100 SW 62nd Ave, Miami, FL 33155).

COMMENT. The authors describe a syndrome of infantile focal facial seizures associated with cerebellar ganglioglioma. Seizures associated with cerebellar tumors in infants and children have been described previously. 